\title{
Peer Teaching and Mathematical Performance of Grade 5 Pupils
}

\author{
Nilda V. San Miguel ${ }^{\mathrm{a}}$, Elymar A. Pascual ${ }^{\mathrm{b}}$ \\ nildssanmiguel@gmail.com \\ Department of Education, Lumban, Laguna, Philippines, 4014 \\ Department of Education, Nagcarlan, Laguna, Philippines, 4002
}

\begin{abstract}
This study aimed in determining the effect of peer teaching to the mathematical performance of Grade 5 Pupils of San Juan Elementary School. Two strategies were executed by the researchers in order analyze the performance of 40 pupils. For the direct teaching, the teacher delivered the topic on "Finding the Area of the Triangle and Parallelogram" with proper procedure - from motivation to evaluation. For the peer teaching, the abstraction part of the lesson was executed through peer teaching with assigned leaders who assist their classmates in understanding the topic. The result of evaluation was documented. Using direct teaching, the 40 pupils obtained a mean of 2.15 and sd 1.66 in a 5 -item quiz. On the other hand, peer teaching generated a mean of 3.55 and sd 1.38. Lower coefficient of variation was observed in the result of peer teaching (0.39) than the result of direct teaching $(0.77)$, showing that peer teaching generated a less varied scores than direct teaching. Using t-test for independent samples, assuming equal variances, the t-computed was -4.11 while the t-critical was 1.99. These values showed that peer teaching has significant effect to the mathematical performance of the pupils. The conclusion is supported by the p-value 0.00. Based on the result of this study, recommendations to Mathematics teachers, school heads, district supervisors and future researchers were given at the end of the study. Promotion of peer teaching should be one of the foci of educators so as to improve mathematical performance of pupils. The teacher-researchers reflected also on the importance of involving the learners on the process of teaching-learning as they themselves are the center and not the teachers.
\end{abstract}

Keywords: peer teaching; academic performance; Mathematics

\section{Introduction}

Mathematics education is one of the core subjects in the K-12. Basic Education Program of the Department of Education. But we cannot deny that most of the learners in the elementary are unprepared for learning mathematics. The understanding level was shown by their low achievements in National Achievement Test particularly in Mathematics.

According to Gan, (2008) the conventional teaching approach usually involve teacher starting the lesson by introducing the topic or concept, explaining it and give some works examples. Lastly, the teacher gives homework to the students. In this kind of learning situation, students are not able to construct their own understanding since they are not actively participating in the teaching and learning process. Students are not able to think to think creatively since they only received what have been taught to them.

In addition, students are not able to keep with the teaching pace. Hence, in order to promote active participation of students, teachers should adjust their teaching styles to a more learner-centered one. One possible teaching approach is the peer- tutoring teaching approach. On the other hand peer-tutoring is systematic, peer/mediated teaching strategy. (Rohrbeck, Ginsburg-Block, Fantuzzo \& Miller, 2003)

\subsection{Background of the Study}

Performance in mathematics depends largely on effective teaching and learning process (UNESCO, 2008). Developmental learning theorists brought to education the idea that teachers can be more effective if 

experiences

(Piaget, 1953). The activities selected in the teaching and learning of mathematics must nurture plenty of student activity and acquisition of learning skills and that an enabling environment should be created to give the learner the opportunity to interact freely with fellow learners.

For effective acquisition of mathematical skills teachers are advised to use heuristic methods as much as possible so as to involve the learners and keep them interested in the subject. They should have a free hand to use their own approaches (KIE, 2006).

The teacher would like to investigate the possible significant effect of peer teaching learning style to the students' academic performance in Mathematics. The teacher taught how to find the Area of the Triangle and Parallelogram not applying the peer teaching learning style, a 5-item word problem quiz was given and the result is recorded. The following day, classroom session with the same topic was held integrating the peer teaching learning style, a 5-item word problem quiz was given and the result was again recorded. The whole result of this investigation is recorded in this study.

\subsection{Theoretical Framework}

The concept of learning through peer teaching is based on a social constructivist view of learning that emphasizes the role of students to generate learning where students coach peers through social interaction within their zones of proximal development (Vygotski, 1978 as cited by Clarkson \& Luca 2002). Rather than applying a stimulus response process, users are actively engaged in making meaning through cognitive accommodation and or simulation. (Piaget 1969, as cited Clarkson \$ Luca 2002).

Social constructivist approaches can include peer collaboration, cognitive apprenticeship, problembased instruction, web-quests, anchored instruction and other methods that involve learning with others (Kim, 2001).

Vygotski argued that learning comes about through social recognition within a cultural context, with language as a primary tool. This social constructivist philosophy has been expanded on recently, introducing the notion of cognitive apprenticeship (Brown, Collins, \& Duguid, 1989 as cited Clarkson \& Luca 2002) through which students learns in manner similar to traditional apprenticeship. The students access expertise through mentors, whose role is to facilitate rather than to teach. For a peer tutor, this setting is a very realistic human setting. Just as in a traditional apprenticeship, learners engage in activities "on the job" rather than through a didactic teaching of abstract concepts. The argument is that students are better equipped to approach non-familiar and produce solutions that are appropriate to a given culture.

\subsection{Conceptual Framework}

The figure shows the conceptual model of this study.

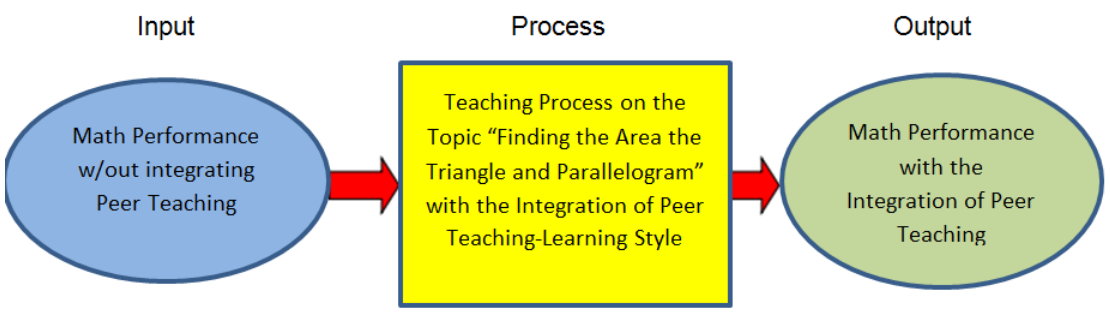

The input shows Math Performance without integrating Peer Teaching learning style. For the Process, the researcher integrated Peer Teaching learning style during teaching-learning process. And for the output, the teacher gave a 5-item word problem quiz and recorded the result of the learners' performance. 
This study will aim to determine if the integrating peer teaching learning style will increase the academic performance of Grade 5 learners in San Juan Elementary School.

Specifically, it seeks to answer the following question.

- What is the mean level of academic performance of Grade 5 learners of San Juan Elementary School in Mathematics not applying peer teaching learning style?

- What is the mean level of academic performance of Grade 5 learners of San Juan Elementary School in Mathematics integrating peer teaching learning style?

- Is there a significant difference between the academic performance of learners not integrating and integrating peer teaching learning style?

\subsection{Scope and Limitations}

This study was conducted in the first quarter of the school year 2017-2018, that is, from June to August of 2017 using the learners of Grade 5- Capricorn in Mathematics which is one of the major core subjects in the K-12 Basic Education Program. Forty students became the focus of this study.

\section{Review of Related Literature}

Where there are people, there will be peer pressure and the classroom is no exception. However, while we're use to thinking of peer pressure as something negative (gangs, fraternity, etc.), it often has the potential to be a powerful positive force.

By leading students through some self-awareness activities, we can help create a group of peer who value individualism, practice it in their own lives and encourage others. Students can be effective tutors.

Saif (2004) considered peer teaching as a mutual learning process in which students teach others the desired skills and knowledge with full coordination with their teacher in case there are any comments or questions. However, the teacher should be around always to solve immediately any problems may arise between students.

Researches show that peer teaching is useful and has many benefits for students and teachers. Vasay (2010) reported that peer teaching is helpful for fast learners and slow learners as well. It helps fast learners to master

the concepts related to the course and confidently express their ideas. Slow learners improve and develop their performance and get a better understanding of the terms of the lessons. Peer teaching helps both, fast learners and slow learners in developing important values such as sharing, self-esteem, and self-discipline.

Lord (2001) reported that students working in groups perform better on exams especially questions that involve reasoning and critical thinking skills. Actually; peer teaching, a type of collaborative learning, often happens

spontaneously with a group of students. In fact, educators have found through experience and their research that peer teaching is an effective strategy in helping learners achieve the educational goals.

Al Deeb (2006), states that peer teaching is one of the most effective strategies in the teaching and learning process because it deals with the social as well as the academic side of learning by creating a comfortable environment for teaching and learning.

Although the name 'peer teaching' sounds straight forward, it is in fact a complex process by which a student learns from another student who has more experience and knowledge. Afaneh (2007) considered peer teaching as communication between an excellent student, who is doing very well or who recently completed the course successfully, and another student encountering difficulties in the same course. 


\section{Research Design}

The study adopted in this research is experimental design. According to Blay (2013), this design is used when a researcher would like to find out the effectiveness of one factor towards the change of behaviour to another factor. In this study, the researcher made use of peer teaching to find out if there will be a significant change in academic performance of grade 5 pupils.

\subsection{Population}

The population for this study is the grade 5 learners of San Juan Elementary School, school year 2017-2018. The sections and frequency is presented in the table below.

\begin{tabular}{|c|c|}
\hline Section & Number of Learners \\
\hline Male & 19 \\
\hline Female & 21 \\
\hline Total & 40 \\
\hline
\end{tabular}

3.2. Data Gathering Procedure

Data and results were gathered and analyzed using the following steps undertaken by the teacherresearcher:

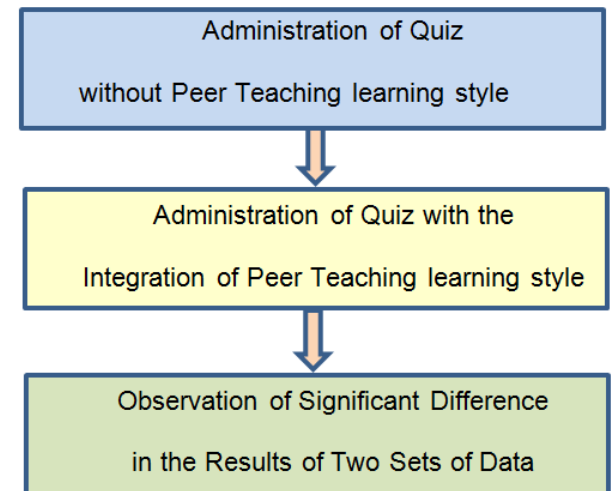

Mean and standard deviation were used to analyze the data gathered from series of quizzes with and without the intervention of Peer Teaching learning style. For the significant difference between the two arrays of data, t-test for independent samples was used.

\section{Presentation, Interpretation and Analysis of Data}

The table shows the result of the of a 5-item word problem quiz given to grade 5 learners of San Juan Elementary School.

\begin{tabular}{|c|c|c|c|c|c|c|c|}
\hline $\begin{array}{c}\text { Teaching } \\
\text { Process }\end{array}$ & $\mathrm{n}$ & Mean & $\mathrm{SD}$ & T-critical & T-computed & P-value & Decision \\
\hline $\begin{array}{c}\text { Without Peer } \\
\text { Teaching } \\
\text { learning style }\end{array}$ & 40 & 2.15 & 1.66 & \multirow[t]{2}{*}{1.99} & \multirow[t]{2}{*}{4.11} & \multirow[t]{2}{*}{0.00} & \multirow[t]{2}{*}{ Significant } \\
\hline $\begin{array}{l}\text { With Peer } \\
\text { Teaching }\end{array}$ & 40 & 3.56 & 1.38 & & & & \\
\hline
\end{tabular}


The two teaching processes being compared are classroom sessions without the integration of peer teaching learning style and classroom sessions with the integration of peer teaching learning style. Without the integration of peer teaching learning style, the learners got a mean of 2.15 and an SD of 1.66 out of a 5item word problem quiz on the topic of "Finding the Area of the Triangle and Parallelogram". On the other hand, with the integration of peer teaching learning style, the learners' mean is 3.56 and SD is 1.38. This shows that learners did better in the teaching-learning process when peer teaching learning style was integrated to learn concepts and skill in Mathematics. Using t-test for independent samples, the T-critical is 1.99 while the T-computed is 4.11. Since the absolute value of the T-computed is greater than the T-critical, it can be said that there is a significant difference between the two means. The P-value 0.00 which is lower than the alpha 0.05 supports the claim that there is a significant difference between the scores in quiz without the integration of peer teaching learning style and with the integration of peer teaching learning style, thus, the implication that the teaching process affects the Mathematical performance of grade 5 learners. When integration of peer teaching learning style is used alongside teaching and learning, higher Mathematical performance is exhibited by the learners compare with the teaching process without the integration of peer teaching learning style. These findings reveal that peer teaching is of great value to the teaching of mathematics. This is in agreement with Puchner (2003) who found that the elaboration of a topic by the student himself and the presentation of this in the classroom may under proper conditions; prove to be a very useful tool in the teaching process for the teacher and the learners.

\section{Recommendations}

Based from the result of this study, the researcher recommends the following to targeted person or group of people:

- Math teachers should embraced peer teaching learning style as a teaching method to help improve students' academic performance in mathematics and to help them develop confidence in mathematics through their direct involvement.

- Department heads may initiate projects, seminar and workshops that would encourage teachers to delve into different learning styles that would victual different kinds of learners.

- Schools heads may encourage teachers to apply in the teaching process the peer teaching learning style so as to improve the students' performance not only in Mathematics but in other subjects also.

- Parents and community can go along with the school is aiming by participating and communicating with the school with regards to what they can do or how they can help in the promotion of different learning styles which in turn would benefit their children and the citizen of the community.

- Future researchers can further investigate on the effect of different learning styles in promoting excellence in teaching.

\section{References}

Afaneh. A. (2007). Teaching Mathematics Strategies. Gaza: Islamic University Library.

Al Deeb, M. (2006). Modern Strategies in Cooperative Learning (1st ed.). Cairo: Books World

Blay, B. E. (2013). Elementary Statistics. Anvil Publishing, Inc.

Brown, J.S., Collins, A., \& Duguid, P., (1989). Situated Cognition and the Culture Learning, Educational Researches, 18 (1), $32-42$

Gan (2008). Effect of Peer Tutoring Teaching Strategy on Secondary Schools Students' Academic Achievement in Mathematics

Kim, B. (2001). Social Constructivism. In M. Orey (Ed.), Emerging perspectives on learning, teaching, and technology. Available at http://www.coe.uga.edu/epltt/SocialConstructivism.htm

Lord, T. (2001). 101 reasons for using cooperative learning in biology teaching. The American Biology Teacher, 63(1), 30-38 http://dx.doi.org/10.2307/4451027

Piaget, J. (1953). Origins of Intelligence in the Child. London. Routledge \& Kegan Paul. 
Puchner, L (2003). Children teaching for learning: what happens when children teach others in the classroom? Teaching and Teacher Education. A paper prepared for the Annual Meeting of the American Educational Research Association, April 21 - 25, 2003 , Chicago, Illinois

Rohrbeck, C. A. et al. (2003). Peer-assisted learning interventions with elementary school students: A meta-analytic review. Journal of Educational Psychology, 95(2), 240257.http://dx.doi.org/10.1037/0022-0663.95.2.240

Saif, Kh. (2004). The Effect of Peer Teaching in Improving Mathematics Skills and Attitudes towards Mathematics of the Elementary Students in Kuwait. Educational Journal, 18.

Vasay, E. (2010). The Effect of Peer Teaching in the Performance of Students in Mathematics. E-InternationalScientific Research Journal, 2, 161.

Vygotsky, L. (1978). Mind in society. Cambridge, MA: M.I.T. Press.

UNESCO (2008). EFA Global Monitoring Report. Paris UNESCO 